\title{
О. М. Шевелёва
}

Sheveleva O. M.

\section{РЕЗУАЬТАТЫ ИСПОАЬЗОВАНИЯ ПОРОАНЫХ РЕСУРСОВ КРУПНОГО РОГАТОГО СКОТА ПРИ ПРОИЗВОАСТВЕ ГОВЯАИНЫ В ТЮМЕНСКОЙ ОБААСТИ}

\author{
RESULTS OF THE USE OF CATTL BREED RESOURC ES IN THE PRODUCTION \\ OF BEEF IN THE TYUMEN REGION
}

Изложены результаты научно-хозяйственного опыта по результатам породоиспытания бычков французских мясных пород скота в сравнении с герефордской породой. Научнохозяйственный опыт проведен в условиях откормочной площадки. Бычки французских мясных пород: лимузин, шароле, обрак, салерс и герефордской пород - после отъема от матерей доращивались и откармливались в условиях откормочной площадки. Рационы кормления разработаны для получения прироста на уровне 950-1100 г. Показатели французских пород сравнивались с показателями герефордской породы.

Породная принадлежность животных оказала влияние на величину живой массы. К концу периода выращивания наибольшая живая масса была у бычков породы шароле 587,5 кг, это больше по сравнению с герефордской породой на 114,4 кг (21,4 \%). Животные лимузинской породы превышали сверстников герефордской породы на 64,4 кг (13,6 \%), обрак - на 7,8 \% и салерс - на 48,1 кг или 10,1 \%. Бычки всех пород имели высокую интенсивность роста. Среднесуточный прирост за период выращивания составил у бычков породы шароле 1120 г, у лимузинской породы 1004 г, салерс 914,2 и обрак - 905,8 г.

При убое в возрасте 18 месяцев были получены тяжеловесные туши. Наибольшая масса парной туши у животных породы шароле - 331,7 кг, у лимузинской - 309,4 кг, обрак 305,3 кг, салерс - 292,6 и герефордской породы - 256,2 кг. Бычки породы шароле по показателям мясной продуктивности, таким как выход туши, убойная масса, имели преимущество над сверстниками других пород. Туши бычков французских пород в большей степени соответствовали требованиям потребителя по сравнению с тушами герефордской породы.

Ключевые слова: порода, лимузин, шароле, обрак, салерс, герефорд, мясная продуктивность, живая масса, прирост.
The article presents the results of the scientific and economic experience based on the results of the breeding of bulls of the French meat breeds of livestock in comparison with the Hereford breed. The scientific and economic experience was carried out in the conditions of the fattening site. Bulls of the French meat breeds: Limousine, Charolais, Aubrac, Salers and Hereford breeds, after weaning from mothers were grown and fattened in conditions of the fattening area. Feed diets are designed to gain growth at the level of 950-1100 g. Indicators of the French breeds were compared with the parameters of Hereford breed.

Animal affinity of animals affected the size of live weight. By the end of the growing period, the largest live weight of the Charolais bulls was $587.5 \mathrm{~kg}$, which is $114.4 \mathrm{~kg}(21.4 \%)$ more, compared to the Hereford ones. Animals of the Limousine breed exceeded that of the Hereford breed by $64.4 \mathrm{~kg}(13.6 \%$,) by $7.8 \%$, and the Salers by $48.1 \mathrm{~kg}$ or $10.1 \%$. Bulls of all breeds had a high growth rate. The average daily gain for the period of cultivation was $1120 \mathrm{~g}$ in gobies of the Charolais breed, $1004 \mathrm{~g}$ in the Limousine breed, 914.2 in the Salers and at $905.8 \mathrm{~g}$ in the Salers.

At slaughter, at the age of 18 months, heavy carcasses were obtained. The greatest weight of the carcasses in the Charolais breeds is $331.7 \mathrm{~kg}$, in the Limousine breed - 309.4 $\mathrm{kg}$, for example - 305.3 the Salers - 292.6 and the Hereford breed $-256.2 \mathrm{~kg}$. The bulls of the Charolais breed in terms of meat productivity, such as carcass yield, slaughter mass had an advantage over peers of other breeds. Carcasses of gobies of the French breeds in a greater degree corresponded to requirements of the consumer, in comparison with carcasses of the Hereford breed.

Key words: breed, Limousine, Charolais, Aubrac. Salers, Hereford, meat production, live weight.

\author{
Sheveleva Olga Mikhailovna - \\ Doctor of Agricultural Sciences, Head of the Department \\ of Technology of Production and Processing \\ of Livestock Products \\ FSBEI HE «Northern Trans-Ural State Agrarian \\ University» \\ Tyumen \\ Tel.: 7-963-068-31-86 \\ E-mail: olgasheveleva@mail.ru
}

И нтенсификация производства говядины во многом определяется породой скота [1]. Научно обоснованный выбор эффективной породы скота для России в связи с большим разнообразием природных-климатических условий имеет большое значение $[2,3]$.

В связи с этим важно выяснить, какие породы скота наиболее приемлемы для развития мясного скотоводства в Северном Зауралье [4]. В Тюменской области разводится четыре французские породы мясного направления продуктивности: лимузин, шароле, салерс и обрак [5]. Кроме того, длительное время используется герефордская порода крупного рогатого скота [6]. Поэтому изучение мясной продуктивности французских мясных пород в условиях откормочной площадки является актуальным. 
Цель работы - провести породоиспытание французских мясных пород в сравнении с герефордской в условиях откормочной площадки.

Исходя из цели были сформулированы следующие задачи:

1. Изучить живую массы и приросты бычков французских мясных пород в условиях откормочной площадки.

2. Провести сравнительную оценку показателей мясной продуктивности молодняка французских мясных пород в сравнении с герефордской.

Исследования проведены в ООО «Кировское» Тюменской области.

Бычки мясных пород до отъема от матерей в возрасте 210-220 дней содержались по технологии мясного скотоводства в племенных репродукторах ООО «Тюменская мясная компания».

После отъема были сформированы группы мясных пород: 1 группа - контрольная, сформирована из бычков герефордской породы; 2-5 группы сформированы из бычков французских мясных пород. Бычки лимузинской породы вошли во 2-ю группу, шароле - в 3-ю, обрак - в 4-ю, салерс - в 5-ю группу. Количество животных каждой группы составило 15 голов. Дальнейшее доращивание и откорм происходили в условиях откормочной площадки.

Для изучения динамики живой массы бычков взвешивали в возрасте 9, 12, 15 и 18 месяцев. На основании данных живой массы был рассчитан среднесуточный прирост в разные возрастные периоды по каждой группе. В возрасте 18 месяцев провели контрольный убой на Ялуторовском мясокомбинате, по три головы из каждой группы. Контрольный убой проведен по методике ВАСХНИЛ, ВИЖ, ВНИМП (1997). При проведении контрольного убоя определяли живую массу, массу парной туши, выход туши, масса внутреннего жира, убойный выход. Для изучения морфологического состава туш проведена обвалка полутуш по технологии мясной промышленности. Химический анализ мяса-фарша проводили в ФГБУ государственной станции агрохимической службы «Тюменская» (аттестат аккредитации RA.RU.21 ПЧЗ7).

Бычки содержались беспривязно, на глубокой несменяемой подстилке в стационарном помещении, со свободным выходом на выгульнокормовые площадки. Поение осуществлялось из групповых поилок с электроподогревом.

Условия содержания и кормления животных всех пород были одинаковы и соответствовали технологии, принятой в мясном скотоводстве. Рационы кормления были разработаны с учетом возраста и живой массы бычков для получения прироста на уровне 1000-1100 г. В структуре рациона концентраты составляли 33 \%, грубые корма - 30, сочные - $37 \%$.

Благоприятные условия кормления и содержания во многом определили интенсивное увеличение живой массы молодняка. Животные всех опытных групп показали высокую интенсивность роста. Породная принадлежность животных определила разницу в величине живой массы. Бычки французских мясных пород имели преимущество по величине живой массы над сверстниками герефордской породы.

Динамика живой массы бычков приведена в таблице1.

У бычков породы шароле в возрасте одного года живая масса составила 389,5 кг, такую же величину этого показателя имели животные породы обрак.

Остальные французские породы незначительно уступают по величине живой массы бычкам породы шароле и обрак. Преимущество французских пород в величине живой массы составило от 52,9 до 57,1 кг ( $\mathrm{P} \geq 0,99)$.

К возрасту 18 месяцев наибольшая живая масса была у быков породы шароле - 587,5 кг, это больше по сравнению с герефордской породой на 114,0 кг (24,1\%). Животные лимузинской породы превышали сверстников герефордской породы на 64,4 кг (13,6\%), обрак - на 7,8 \% и салерс - на 48, 1 кг, или $10,1 \%$.

Таблица 1 - Динамика живой массы и среднесуточный прирост бычков

\begin{tabular}{|c|c|c|c|c|c|}
\hline \multirow{2}{*}{$\begin{array}{c}\text { Возраст, мес., } \\
\text { периоды роста }\end{array}$} & I & II & III & IV & V \\
\cline { 2 - 6 } & \multicolumn{7}{|c|}{ Живая масса, кг } & гуппа животных \\
\hline 9 & $245,2 \pm 8,1$ & $289,6 \pm 9,2 * *$ & $279,4 \pm 3,3 *$ & $299,4 \pm 2,7 * *$ & $300,2 \pm 9,5 * * *$ \\
\hline 12 & $332,4 \pm 7,4$ & $387,8 \pm 10,6 * * *$ & $389,5 \pm 3,2 * * *$ & $389,5 \pm 3,1 * * *$ & $385,3 \pm 8,1 * * *$ \\
\hline 15 & $427,6 \pm 6,3$ & $489,9 \pm 5,8 * * *$ & $498,7 \pm 4,8 * * *$ & $475,2 \pm 5,4 * *$ & $478,2 \pm 6,4 * *$ \\
\hline 18 & $473,5 \pm 6,1$ & $537,9 \pm 21,4 * * *$ & $498,7 \pm 4,8 * * *$ & $510,5 \pm 6,3 * * *$ & $521,6 \pm 18,3 * * *$ \\
\hline $9-12$ & $968,9 \pm 27,3$ & $1091,1 \pm 26,6$ & $1223,3 \pm 35,1$ & $1001,1 \pm 26,6$ & $945,6 \pm 31,2$ \\
\hline $12-15$ & $862,2 \pm 35$, & $1134,4 \pm 37,1$ & $1213,3 \pm 26,2$ & $959,2 \pm 28,3$ & $1032,2 \pm 36,5$ \\
\hline $15-18$ & $705,6 \pm 32,4$ & $844,4 \pm 28,3$ & $986,7 \pm 28,1$ & $814,4 \pm 15,2$ & $815,6 \pm 36,7$ \\
\hline $9-18$ & $831,0 \pm 32,2$ & $831,0 \pm 32,2$ & $1120,3 \pm 29,8$ & $905,8 \pm 23,4$ & $914,2 \pm 34,8$ \\
\hline
\end{tabular}


Величина среднесуточных приростов подтверждает выявленную закономерность о высокой интенсивности роста молодняка всех пород, что объясняется полноценным кормлением животных.

Наиболее высокие приросты наблюдаются у животных породы шароле. В период с 9- до 12-месячного возраста величина прироста у животных породы шароле составила 1223 г, что превышает эту величину у бычков герефордской породы на 254,4 г, или 26,2 \%. Среднесуточный прирост бычков лимузинской породы составил 1091 г. Бычки породы обрак превышают величину среднесуточного прироста бычков герефордской породы на 32,1 г (3,3 \%). У бычков породы салерс в период с 9- до 12-месячного возраста наблюдались более низкие приросты по сравнению с герефордскими бычками.

За весь период выращивания среднесуточный прирост у бычков породы шароле составил 1120 г, у лимузинская породы - 1004 г, салерс 914,2 и обрак - 905,8 г. У бычков герефордской породы соответственно среднесуточный прирост был меньше, чем у французских пород, на 289,3-74,8 г. Интенсивное выращивание сказалось на формировании мясного типа телосложения животных, у них формировался широкотелый тип телосложения с хорошо выраженными мясными формами.

По данным контрольного убоя, проведенного в возрасте 18 месяцев, установлено, что бычки всех пород дали тяжеловесные, хорошо обмусленные туши. Результаты контрольного убоя представлены в таблице 2.

Туши всех пород крупного рогатого скота были покрыты тонким слоем подкожного жира.

Наиболее массивные туши были получены от животных породы шароле. Масса парной туши составила 331,7 кг, что меньше по срав- нению с тушами быков герефордской породы на 75,5 кг (29,4 \%). По величине массы парной туши лимузинских бычков по сравнению с герефордскими превосходство составило 53,0 кг, обрак - 49,1 кг и салерс 36,4 кг соответственно в сравнении с герефорскими бычками $(P \geq 0,99)$. Ранг распределения пород повторился и по убойной массе, в то время как по массе жира-сырца преимущество имели бычки герефордской породы. Это объясняется большей скороспелостью герефордской породы. Максимально высокий выход туши был у животных породы шароле. Однако значительные различия по массе внутреннего жира-сырца обусловили более высокий убойный выход молодняка герефордской породы.

Наши данные согласуются с ранее проведенными исследованиями [7, 8].

Важным показателем, характеризующим мясную продуктивность, является морфологический состав туш [9]. При проведении обвалки туш от животных всех пород получен высокий выход мышечной ткани. Туши бычков французских мясных пород в большей степени соответствовали требованиям потребителя, предпочитающего менее жирное мясо. Максимальное содержание мякотной части было характерно для бычков породы шароле - 130,8 кг, что больше, чем от герефордских бычков, на 34,5 кг (35,8 \%). Преимущество лимузинской породы составило 26,0 кг, обрак - 23,3, салерс - 13,2 кг относительно герефордской породы. Меньшим содержание костной ткани в абсолютном и относительном выражении характеризовались бычки герефордской породы. Наибольшее количество костной ткани получено от животных породы шароле - 30,4 кг, самый высокий выход костной ткани от животных породы салерс $19,3 \%$.

Таблица 2 - Результаты контрольного убоя бычков

\begin{tabular}{|l|c|c|c|c|c|}
\hline \multicolumn{1}{|c|}{ Показатель } & \multicolumn{5}{|c|}{ Порода } \\
\cline { 2 - 6 } $\begin{array}{l}\text { Предубойная } \\
\text { масса, кг }\end{array}$ & $460,5 \pm 11,2$ & $541,0 \pm 12,2$ & $569,0 \pm 9,2 * *$ & $530,0 * \pm 8,6$ & $141,6 \pm 3,2 * *$ \\
\hline $\begin{array}{l}\text { Масса парной } \\
\text { туши, кг }\end{array}$ & $256,2 \pm 4,6$ & $309,4 \pm 5,2 * *$ & $331,7 \pm 4,6 * *$ & $305,3 \pm 6,2 * *$ & $292,6 \pm 7,5 * *$ \\
\hline Выход туши, \% & 55,7 & 57,2 & 58,3 & 57,6 & 54,8 \\
\hline $\begin{array}{l}\text { Масса внутрен- } \\
\text { него жира, кг }\end{array}$ & $256,2 \pm 4,6$ & $18,9 \pm 0,2 * * *$ & $15,9 \pm 4,6 * *$ & $19,1 \pm 6,2 * *$ & $20,8 \pm 0,5 * *$ \\
\hline $\begin{array}{l}\text { Выход внутрен- } \\
\text { него жира, \% }\end{array}$ & 6,2 & 3,5 & 2,8 & 3,6 & 3,9 \\
\hline $\begin{array}{l}\text { Убойная масса, } \\
\text { кг }\end{array}$ & $284,7 \pm 14,7$ & $328,3 \pm 5,3$ & $347,6 \pm 4,5$ & $324,4 \pm 6,5$ & $313,4 \pm 7,5$ \\
\hline $\begin{array}{l}\text { Убойный выход, } \\
\%\end{array}$ & 61,9 & 60,7 & 61,1 & 61,2 & 58,7 \\
\hline $\begin{array}{l}\text { Выход, \%: } \\
\text { мякоти }\end{array}$ & 78,9 & 78,9 & 79,3 & 78,2 & 77,6 \\
\hline кости & 18,1 & 18,2 & 18,4 & 18,9 & 19,3 \\
\hline $\begin{array}{l}\text { сухожилия } \\
\text { и хрящи }\end{array}$ & 3,2 & 3,9 & 4,3 & 4,3 & 4,1 \\
\hline
\end{tabular}




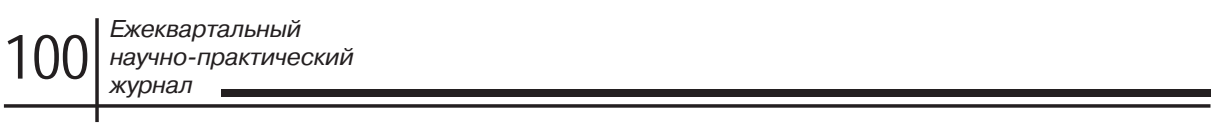

Таблица 3 - Химический состав мяса-фарша $\left(\mathrm{X} \pm \mathrm{S}_{\mathrm{x}}\right)$

\begin{tabular}{|l|c|c|c|c|}
\hline \multicolumn{1}{|c|}{ Порода } & Сухое вещество & Жир & Протеин & Зола \\
\hline Герефордская & $31,8 \pm 0,8$ & $10,6 \pm 0,13$ & $20,1 \pm 0,7$ & $1,1 \pm 0,03$ \\
\hline Лимузин & $28,9,0 \pm 0,25^{*}$ & $3,4 \pm 0,03^{* * *}$ & $24,6 \pm 0,6 * *$ & $0,9 \pm 0,02$ \\
\hline Шароле & $27,6 \pm 0,5^{*}$ & $3,6 \pm 0,15^{* * *}$ & $23,1 \pm 0,4 * *$ & $0,9 \pm 0,03$ \\
\hline Обрак & $29,1 \pm 0,12^{*}$ & $4,3 \pm 0,13^{* * *}$ & $23,7 \pm 0,3^{* *}$ & $1,1 \pm 0,04$ \\
\hline Салерс & $28,7 \pm 0,2^{*}$ & $4,6 \pm 0,11^{* * *}$ & $23,1 \pm 1,5$ & $1,0 \pm 0,05$ \\
\hline
\end{tabular}

Выход мякоти на 1 кг костей у животных герефордской породы составил 4 кг, у животных французских мясных пород - от 4,0 до 4,3. Таким образом, ни у одной породы коэффициент мясности не достиг параметров высококачественного мяса. Полученные результаты не противоречат ранее проведенным исследованиям по изучению мясной продуктивности французских мясных пород скота [10].

Питательная ценность говядины во многом зависит от ее химического состава [11]. Анализ химического состава средней пробы мясафарша показал, что герефордская порода имела преимущество по количеству сухого вещества в мясе фарше по сравнению с французскими мясными породами скота. Процесс интенсивного отложения жира в тушах животных герефордской породы повлиял на содержание сухого вещества в силу их относительной скороспелости. Наибольшее содержание протеина в мясе-фарше бычков лимузинской породы, хи- мический состав приведен в таблице 3. Аналогичные результаты были получены в ранее проведенных исследованиях.

Таким образом, интенсивное выращивание и откорм бычков мясных пород в условиях Северного Зауралья обеспечивает высокие показатели мясной продуктивности у пород французского корня происхождения. Масса парной туши у животных породы шароле составила 331,7 кг, у лимузинской - 309,4 кг, обрак - 305,3, салерс 292,6 и герефордской породы - 256,2 кг. По основным показателям мясной продуктивности, таким как выход туши, убойная масса, лучшими были бычки породы шароле, что свидетельствует об их высоком потенциале мясной продуктивности. Наиболее высокое содержание сухого вещества было в мясе-фарше бычков породы герефорд, за счет более высокого содержания жира. При этом химический состав мяса-фарша свидетельствует о хороших качественных показателях мяса, полученного от всех пород скота.

\section{Литература}

1. Проект концепции устойчивого развития мясного скотоводства в Российской Федерации до 2030 года / Х. А. Амерханов, С. А. Мирошников, Р. В. Костюк [и др.] // Вестник мясного скотоводства. 2017. № 1 (97). С. 7-11.

2. Легошин Г. П., Алексеев А. А. Эффективность разведения и использования мясных коров в условиях инновационной технологии // Молочное и мясное скотоводство. 2017. № 4. С. 26-29.

3. Дунин И. М. Племенные ресурсы специализированного мясного скотоводства основа интенсивного производства говядины в России // Зоотехния. 2018. № 2.

4. Гамарник Н. Г., Шевелёва О. М., Дуров А. С. Герефордский скот сибирской селекции : моногр. Новосибирск : ГНУ СибНСХБ, 2010. 309 с.

5. Бахарев А. А., Шевелёва О. М. Особенности мясной продуктивности бычков породы салерс в процессе их акклиматизации в условиях Северного Зауралья // Молочное и мясное скотоводство. 2017. № 8. С. 27- 30.

6. Бахарев А. А., Шевелёва О. М., Беседина Г. Н. Характеристика и история форми-

\section{References}

1. The draft concept of sustainable development of beef cattle in the Russian Federation up to 2030 / by H. A. Amirkhanov, S. A. Miroshnikov, R. V. Kostiuk [et al.] // Bulletin of beef cattle. 2017. № 1 (97). P. 7-11.

2. Legoshin G. P., Alekseev A. A. Efficiency of breeding and use of meat cows in the conditions of innovative technology // Dairy and beef cattle. 2017. № 4. P. 26-29.

3. Dunin I. M. Breeding resources of specialized meat cattle breeding-the basis of intensive beef production in Russia // Zootechnics. 2018. № 2.

4. Gamarnik N. G., Sheveleva O. M., Durov A. S. Hereford cattle of Siberian selection : monograph. Novosibirsk : SSI Siberian agricultural library of the Russian Academy of agricultural sciences, 2010. 309 p.

5. Bakharev A. A., Sheveleva O. M. Features of meat productivity of bulls of breed Salers in the course of their acclimatization in the conditions of the Northern Trans-Ural // Dairy and meat cattle breeding. 2017. № 8. P. 27-30.

6. Bakharev A. A., Sheveleva O. M., Besedina G. N. The characteristics and the history of the formation of beef cattle in the Tyu- 
рования мясного скотоводства Тюменской области // Мир инноваций. 2017. № 1. С. 65-69.

7. Лысенко Л. А., Шевелёва О. М. Рост, развитие и гематологические показатели крупного рогатого скота обракской породы различных генераций в условиях Северного Зауралья // Сибирский вестник сельскохозяйственной науки. 2008. № 11. С. $23-27$.

8. Шевелёва О. М., Логинов С. В. Живая масса и показатели роста быков мясных пород в условиях Северного Зауралья // Агропродовольственная политика России. 2016. № 8 (56). С. 24- 27.

9. Шевелёва О. М., Логинов С. В. Сравнительная оценка мясной продуктивности бычков разных пород в условиях Северного Зауралья // Известия Оренбургского ГАУ. 2017. № 5 (67). С. 158-160.

10. Шевелёва О. М., Бахарев А. А., Криницина Т. П. Мясное скотоводство Тюменской области // Современная наука - агропромышленному производству : сб. науч. тр. по материалам Междунар. науч-практ. конф., посвящ. 135-летию первого среднего учебного заведения Зауралья - Александровского реального училища и 55летию ГАУ Северного Зауралья. Тюмень, 2014. C. 148- 150.

11. Шевелёва О. М., Бахарев А. А. Мясная продуктивность бычков породы салерс разных генетико-экологических генераций // Молочное и мясное скотоводство. 2013. № 8. С. 25-26. men region // World of innovation. 2017. № 1. P. 65-69.

7. Lysenko L. A., Sheveleva O. M. Growth, development and hematological indicators of cattle of the obrak breed of various generations in the conditions of the Northern TransUral // Siberian Bulletin of agricultural science. 2008. № 11. P. 23-27.

8. Sheveleva O. M., Loginov S. V. Live weight and growth rates of beef breeds in the conditions of the Northern Trans-Ural // Agro-Food policy of Russia. 2016. № 8 (56). P. 24- 27.

9. Sheveleva O. M., Loginov S. V. Comparative assessment of meat productivity of bulls of different breeds in the conditions of the Northern Trans-Ural // News of the Orenburg SAU. 2017. № 5 (67). P. 158-160.

10. Sheveleva O. M., Bakharev A. A., Krinitsina T. P. Meat cattle breeding of the Tyumen region // Modern science-agro-industrial production : collection of scientific papers on the materials of the International scientific and practical conference dedicated to 135th anniversary of the first secondary school of the Trans-Urals - Alexander real school and 55 th anniversary of the Northern Trans-Urals. Tyumen, 2014. P. 148-150.

11. Sheveleva O. M., Bakharev A. A. Meat productivity of Salers bulls of different genetic and ecological generations // Dairy and meat cattle breeding. 2013. № 8. P. 25-26. 